\title{
Can one lab make a difference?
}

\author{
David S. Abbott, Jeffery M. Saul, George W. Parker, and Robert J. Beichner \\ Department of Physics, North Carolina State University, Raleigh, North Carolina 27695
}

(Received 17 February 2000; accepted 22 May 2000)

\section{INTRODUCTION}

Many studies ${ }^{1}$ have demonstrated that carefully constructed active learning activities ${ }^{2}$ can improve student conceptual understanding. However, only a few studies, all involving the use of microcomputer-based laboratory (MBL) based mechanics activities, have shown significant improvement resulting from a single isolated treatment in the context of a traditional lecture class. ${ }^{3-6}$ We wanted to see whether replacing a single traditional laboratory activity with a widely used, non-MBL, research-based activity could produce improved conceptual understanding for a topic in electricity.

All students in this study were in the same lecture section of the second semester introductory physics course for engineers at North Carolina State University (NCSU) during the summer of 1999. The lecture section met for $90 \mathrm{~min}$, five days a week. The instructor (GWP) lectured for $50 \mathrm{~min}$ and then led an in-class problem-solving session for $30 \mathrm{~min}$. One TA taught all lab sections. The 2-h labs met once a week for five weeks. The lab activities are typical of those found in introductory physics courses at many colleges and universities. There was no separate discussion/recitation section.

The instruction for all students in the study was the same except for a single 2-h laboratory period. For the dc circuits lab, students were split into two groups based on which lab section they attended. The students in the experimental group (EXP) did a single activity based on the two batteries and bulbs activities from Tutorials in Introductory Physics. ${ }^{7}$ Instead of a traditional lab report, the EXP students were assigned a worksheet that combines elements of the suggested homework assignments that accompany the two Tutorials. ${ }^{8}$ The students in the control group (TRD) carried out a more traditional Ohm's law activity from the NCSU lab manual ${ }^{9}$ and prepared a standard lab report. An experienced TA familiar with the traditional labs taught all lab sections. To prepare for the Tutorial, the TA met with one of the authors (DSA), took the Pretest, and worked through the activity.

It is important to note that, while Shaffer and McDermott have shown that the dc circuit Tutorials can improve student performance on qualitative problems when used as part of a series of Tutorial activities, ${ }^{10}$ individual Tutorials are not intended to be used as "stand alone", activities.

Student understanding was measured by performance on items from course tests and a dc circuits pretest (described below). Only students who were enrolled in lab and took all the tests, including the dc circuits pretest, were included in the study. There were 20 students in the EXP group and 18 students in the TRD group.

\section{RESULTS}

The students took the first course exam before any instruction on dc circuits. The exam scores for both groups were virtually identical (EXP-77\% vs TRD-76\%, $t=0.4, p$ $=0.7$ ). A $15-\mathrm{min}$, free response dc circuits pretest ${ }^{11}$ was given at the end of the lecture session on the day that resistive circuits were introduced and before the lab on dc circuits. The pretest was a shortened combination of the two Tutorial Pretests. ${ }^{11}$ Both groups did very poorly on the pretest, with the EXP group scoring somewhat lower than the TRD group, although the difference is not statistically significant (EXP-28\% vs TRD-37\%, $t=-1.9, p=0.06)$.

Student understanding after instruction on dc circuits was measured by performance on 14 multiple choice items from the second unit test and the final exam. The course instructor, who has made up the common exams at NCSU for many years, chose eight of these questions from a bank of past common exam questions. The remaining six questions were selected by two of the authors (JMS and DSA) from DIRECT, a 29 item multiple-choice dc circuits concept test. $^{12}$

Students in the EXP group did significantly better overall on the six DIRECT questions (EXP-60\% vs TRD-37\%, $t=2.6, p=0.01$ ), outscoring the TRD group by $10 \%-40 \%$ on each question. While one DIRECT question (29) closely resembles the Tutorial activity, removing this item from the comparison still yields a statistically significant result (EXP-62\% vs TRD-42\%, $t=2.0, p=0.04)$. The results imply that, at least for the situation established during this study, a single instructional experience utilizing the researchbased Tutorial materials was noticeably better at helping students understand dc circuits concepts than a traditional laboratory experience on the same topic.

Even though traditional test questions, like those used in this study, may not effectively detect differences in the amount of learning between two groups, the results from the eight traditional exam questions are encouraging. The EXP students significantly outperformed the TRD students (EXP-90\% vs TRD-55\%,t $=2.4, p=0.03$ ) on one test question, which is analyzed in detail below. There was no difference on the remaining seven questions. On five of these seven questions, students from both groups did extremely well (EXP-88\%, TRD-90\%), with more than $75 \%$ of the students in each group answering each question correctly. The other two questions that showed no difference dealt with topics not addressed by either lab activity.

The EXP students outperformed the TRD students on the question based on the circuit shown in Fig. 1. Students were asked to find the voltage across the battery. The EXP students were apparently able to extend the qualitative analysis from the Tutorial to a similar, but not identical quantitative problem. In the Tutorial, students predict what happens to the brightness of bulb B when the switch is closed in the circuit in Fig. 2 and explain their answer. A series of questions leads students through an analysis of the circuit based 


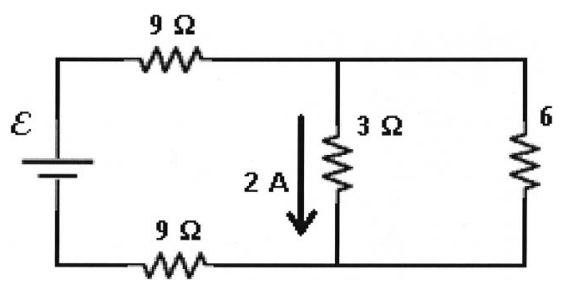

Fig. 1. The circuit students analyzed on the final exam. Students were given the current through the 3- $\Omega$ resistor and asked to find the voltage across the battery.

on junction rule and voltage rule. This method, reinforced by several items in the Tutorial homework, is more useful in solving the question in Fig. 1 than a method based on the equivalent resistance formulas stressed by the activity from the NCSU lab manual. The outstanding performance of the EXP group on this item is especially encouraging, because this problem involves two complications not directly addressed by the Tutorial: quantitative calculation and nonidentical resistors.

\section{CONCLUSIONS}

We found that a single instructional experience utilizing the research-based Tutorial materials was noticeably superior to a traditional quantitative laboratory experience on the same topic for helping students build a conceptual understanding of dc circuits. Not only is the Tutorial activity better than the traditional quantitative lab at promoting conceptual understanding, but the Tutorial appears to be at least as good at promoting successful problem solving.

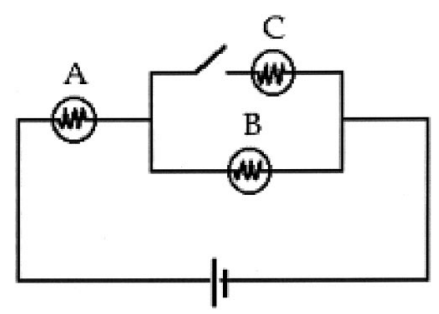

Fig. 2. The circuit students analyzed in the Tutorial and DIRECT item 29. Students were asked to predict what happens to the brightness of each bulb when the switch is opened or closed.
This study suggests the exciting possibility that replacing a single traditional activity may also lead to improved performance on some types of quantitative problems, but more work needs to be done to assess the impact on problem solving. Studying student performance on test items specifically designed to address the strengths and weaknesses of each treatment would provide a better picture of how problem solving was affected by both treatments.

\section{ACKNOWLEDGMENTS}

Mark Reams taught both lab activities, graded two sets of papers, and provided unlimited access to the laboratory classroom. Our colleagues in the Physics Education Research and Development group at North Carolina State University provided valuable input throughout this project. The National Science Foundation supports DA through Grant No. DGE-9554526.

${ }^{1}$ L. C. McDermott and E. F. Redish, "Resource Letter: PER-1: Physics Education Research," Am. J. Phys. 67 (9), 755-768 (1999).

${ }^{2}$ G. J. Posner, K. A. Strike, P. W. Hewson et al., "Accommodation of a scientific conception: Toward a theory of conceptual change,' Sci. Educ. 66 (2), 211-227 (1982).

${ }^{3} \mathrm{H}$. Brasell, "The Effect of Real-time Laboratory Graphing on Learning Graphic Representations of Distance and Velocity," J. Res. Sci. Teach. 24 (4), 385-395 (1987).

${ }^{4}$ R. K. Thornton and D. R. Sokoloff, “'Assessing Student Learning of Newton's Laws: The Force and Motion Conceptual Evaluation and the Evaluation of Active Learning Laboratory and Lecture Curricula," Am. J. Phys. 66 (4), 338-351 (1998).

${ }^{5} \mathrm{~K}$. Cummings, J. Marx, R. Thornton et al., "Evaluating innovation in studio physics," Am. J. Phys. 67 (7), S38-S44 (1999).

${ }^{6}$ E. F. Redish, J. M. Saul, and R. N. Steinberg, "On the effectiveness of active-engagement microcomputer-based laboratories," Am. J. Phys. 65 (1), 45-54 (1997).

${ }^{7}$ L. C. McDermott, P. S. Shaffer, and the Physics Education Group, Tutorials in Introductory Physics (Prentice-Hall, Upper Saddle River, NJ, 1998).

${ }^{8}$ Since students had only 48 hours to complete the homework, the first and fifth pages of the homework for "A model for circuits: Part 2" were eliminated from the homework assignment. The first page reviews material covered in the homework for "A model for circuits: Part 1." The fifth page asks the students to evaluate the discourse between two fictional students.

${ }^{9}$ R. A. Egler, Physics in Action (Contemporary Publishing Company, Raleigh, NC, 1997).

${ }^{10}$ P. S. Shaffer and L. C. McDermott, "Research as a guide for curriculum development: An example from introductory electricity. Part II: Design of an instructional strategy," Am. J. Phys. 60, 1003-1013 (1992).

${ }^{11}$ At the request of the instructor, the pretest was designed to take less than fifteen minutes. The two Pretests from the Instructor's Guide were combined into a single form. Item 2 from the Pretest for Part 1 was dropped.

${ }^{12} \mathrm{P}$. Engelhardt, "Examining students' understanding of electrical circuits through multiple-choice testing and interviews," Ph.D. dissertation, North Carolina State University, 1997.

Caminante, no hay camino, se hace camino al andar. (Wanderer, there is no path. You lay down a path by walking.)

Antonio Machado, Proverbios y Cantares 